\title{
Back calculations of slope failures by the secant method
}

\author{
V. U. NGUYEN (1984). Géotechnique 34, No. 3, 423-427
}

\section{Dr M. Dunbavan, Division of Geomechanics, CSIRO Australia}

This article demonstrates that the use of computers can improve the efficiency of slope stability calculations. Most slope stability analyses require repeated calculations for the determination of the critical location of slip surfaces or values of material shear strength. Instead of using an arbitrary array of geometrical or material property values resulting in the production of a large volume of numbers requiring manual interpretation, optimization techniques borrowed from the field of operations research were applied to the calculations. The repetitive process was essentially eliminated with the use of the published optimization method.

After a slope failure has occurred, the critical kinematically admissible slip mechanism could be identified in most cases. There is a danger that people who use the numerical optimization method might neglect the field evidence from which the valid slip mechanism can be inferred in favour of using the optimization method (on a computer) which gives the 'critical' value of a particular material characteristic. If the incorrect slip mechanism is assumed for a back analysis, the results will be invalid regardless of the solution technique used.

The benefits of using numerical optimization are more evident in slope stability analyses used for design. The design analysis generally involves more unknowns than a similar back analysis and it is the optimization of a functional (e.g. the factor of safety) with respect to a number of variables which improves the efficiency of slope design procedures. The purpose of the numerical optimization procedure is to decrease the time spent in identifying the "worstcase' solution, and it does not necessarily follow that the accuracy of the solution is improved. The accuracy of the critical values depends on the validity of the slip mechanism, the accuracy of the input data and the errors due to assumptions and approximations in the analysis.

Optimization methods similar to the simplex reflection technique have been used previously to improve the efficiency of slope stability calculations. For example, Dunbavan (1980a) used a version of the Powell algorithm (Numerical Algorithms Group, 1976) to find the critical loca- tion of slip planes for a two-wedge slope stability analysis developed from research into spoil pile stability at strip coal mines in Queensland. This two-wedge stability analysis is based on the principle of virtual work and gives a more accurate prediction of the critical location of slip surfaces than do comparable limit equilibrium methods. Table 1 lists the predicted critical locations of slip surfaces using limit equilibrium and virtual work methods as well as the observed locations of slip surfaces at failure in small-scale laboratory slopes (see also Fig. 1). One reason for the better accuracy of predictions from the virtual work method is its compatibility with the sequential development of the two-wedge slip mechanism (Dunbavan, 1980b, 1983). This comparison of analyses for a particular case highlights the influence of inherent inaccuracies in many analyses which might be disregarded when the sophisticated technique of numerical optimization is introduced.

The Author referred to a report published by the CSIRO Division of Geomechanics, by Fuller, McKean, Richards, Cox, Wooltorton \& Toh (1981). Readers are advised that this reference remains confidential to the sponsor of the research, the Utah Development Company. A more recent report on a continuation of that line of research is publicly available (Mallett, Dunbavan, Seedsman \& Ross, 1983).

\section{REFERENCES}

Dunbavan, M. (1980a). Two-wedge stability analysis based on energy principles. Geomechanics of Coal Mining Report No. 17, Division of Geomechanics, CSIRO Australia.

Dunbavan, M. (1980b). Physical modelling of sequential slope failure. Proc. 3rd Australia-N.Z. Conf. Geomechanics, Wellington, pp. 2-41-2-45.

Dunbavan, M. (1983). Program WEDERG-a slope stability wedge analysis. Geomechanics of Coal Mining Report No. 25, Division of Geomechanics, CSIRO Australia.

Mallett, C. W., Dunbavan, M., Seedsman, R. W. \& Ross, D. J. (1983). Stability of spoil piles and highwalls in deep surface mines. Final Report, Project 79/9341, National Energy Research Development and Demonstration Council (Australia).

Numerical Algorithms Group (1976). NAG library manual-rrark. 5, vol. 1, ch. E04. Oxford: Numerical Algorithms Group. 


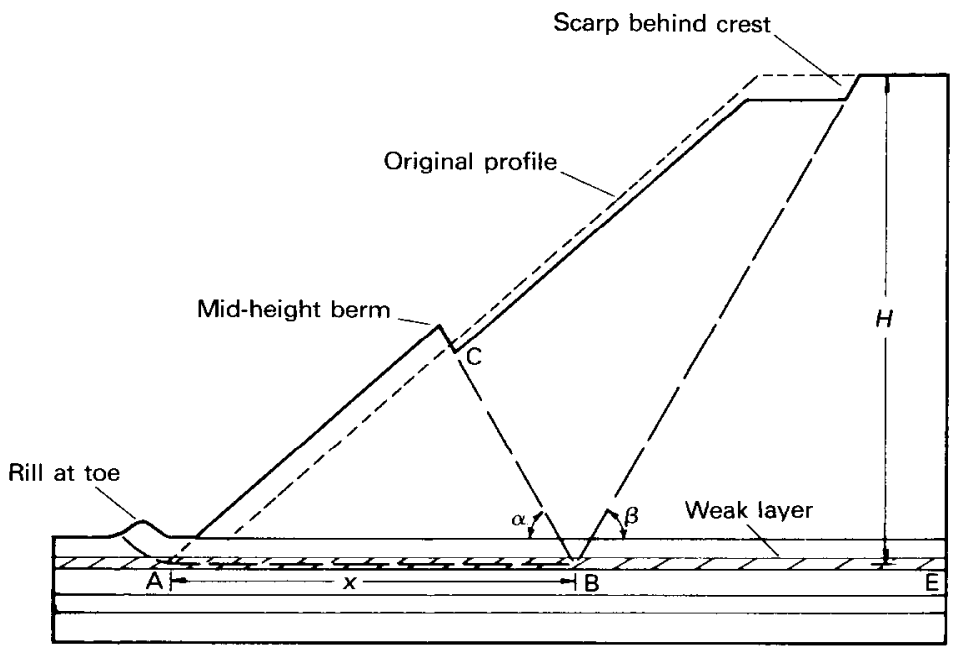

Fig. 1. Characteristic two-wedge slip mechanism

Table 1. Comparison of predictions from stability analyses*

\begin{tabular}{l|c|c|c}
\hline \multicolumn{1}{c|}{ Analysis } & $x / H$ & $\alpha: \operatorname{deg}$ & $\beta: \operatorname{deg}$ \\
\hline $\begin{array}{l}\text { US Army Corps of } \\
\begin{array}{l}\text { Engineers } \\
\text { Rendulic spreading } \\
\text { failure }\end{array}\end{array}$ & $1 \cdot 48$ & 90 & 56.8 \\
$\begin{array}{l}\text { Morgenstern and Price } \\
\text { Virtual work }\end{array}$ & $1 \cdot 2$ & $\begin{array}{c}98 \\
\text { (inferred) } \\
75\end{array}$ & 56.5 \\
\hline Observed & $1 \cdot 20$ & $\begin{array}{c}7.15 \\
70.1\end{array}$ & $\begin{array}{c}75 \\
\pm 10\end{array}$ \\
\hline
\end{tabular}

${ }^{*}$ See Fig. 1 for definition of $x, H, \alpha$ and $\beta$.

\section{Author's reply}

The Writer apologizes for the incorrect reference to the report by Fuller, Richards, Cox, Wooltorton \& Toh (1981).

The importance of identifying failure mechanism before back calculations, as highlighted by Dunbavan, is fully supported by the Writer. In geotechnical practice and literature, however, the identification of the failure mechanism or potential failure modes is often overlooked. This can be observed from the world-wide popularity enjoyed by circular slope analyses and little attention given to other possible modes of slope failure, such as the wedge modes etc.

It was shown in the Technical Note that back calculation can be effectively formulated as an optimization process on the basis of failure definition by the factor of safety being equal to unity. Back calculation or the inverse problem is thus insensitive to the choice of an analytical method used to model the slope failure process.

The Writer also appreciates that the application of the virtual work principle, as pioncered by Drucker \& Prager (1952) in their classic work on soil mechanics and plasticity, can offer an elegant and direct method of calculating the collapse load of a geotechnical structure or the factor of safety of a slope, associated with a kinematically admissible failure configuration. A comparison between analytical predictions and the observed result of a particular set of slope model tests, given by Dunbavan in Table 1 and Fig. 1, clearly illustrates the viability, effectiveness and applicability of the virtual work approach in slope analysis.

Better accuracy obtained in predicting the critical slip surface by the virtual work approach, that could be interpreted from Table 1, however, may not be totally convincing. Of the limit equilibrium methods used in the comparative demonstration, the US Army Corps of Engineers, method already involved a gross assumption on the (vertical) direction of the interwedge slip plane, whereas the MorgensternPrice method and the Rendulic method are not known to be directly formulated on a two-wedge and biplanar mechanism.

It is also not fair that the most accurate prediction of the critical slip surface should be emphatically ascribed to the virtual work method alone, without equal consideration to the Powell method of optimization referred to (Dunbavan, 1980). In this respect, it is disappointing that there has been virtually no published comparison between the energy balance 
method and the limit equilibrium methods formulated on the same type of two-wedge mechanism, incorporating search schemes for the critical slip surface (Coulthard \& Perkins, 1979; Nguyen, 1984), or comparison between the virtual work method and a discretization technique like the finite element method. (Interested readers are referred to a comparative slope stability study of the limit equilibrium method using the simplex reflection routine and the finite elment method, for the circular slip mode, given by Donald, Tan \& Goh (1985).)

Finally, it is of interest to recall that there is little fundamental difference between the virtual work method and the limit equilibrium method since both of thesc methods can be subscribed to the general class of analytical techniques that provides an upper-bound type of solution in slope analysis. The limit equilibrium method, however, falls short of one important consideration pertinent to the compatibility between the strain and the kinematically admissible velocity field, and is generally considered to give a solution that is less conservative than the virtual work or upper-bound solution (e.g. Chen, 1975; Fredlund, 1984).

\section{REFERENCES}

Chen, W. F. (1975). Limit analysis and soil plasticity. Amsterdam: Elsevier.

Coulthard, M. A. \& Perkins, B. R. (1979). Program WEDGE2. Computer Routine No. 28. Melbourne: Division of Geomechanics, CSIRO.

Donald, I, B., Tan, C. P. \& Goh, T. C. ^. (1985). Stability of geomechanical structures assessed by finite element methods. Conf. Computers in Civil Engineering, Hangzhou, June.

Drucker, D. C. \& Prager, W. (1952). Soil mechanics and plastic analysis or limit design. Q. Appl. Maths 10, 157-165.

Dunbavan, M. (1980). Two wedge stability analysis based on energy principles. Geomechanics of Coal Mining Report No. 17, Division of Geomechanics, CSIRO Australia.

Fredlund, D. G. (1984). Analytical methods for slope stability analysis. Proc. 4th Int. Symp. Landslides, Toronto 1, State of the art report, pp. 229-250.

Nguyen, V. U. (1984). Analysis of two-wedge slope failures. Proc. 4th Int. Symp. Landslides, Toronto, 2, 467-471. 